\title{
ASSOCIATIVE AIDS: I. THEIR RELATION TO LEARNING, RETENTION, AND OTHER ASSOCIATIONS
}

\author{
BY H. B. REED \\ University of Idaho
}

The particular problems of this experiment center about (I) the relation of associative aids to the rate of learning and of forgetting; (2) their relation to other associations; (3) their relation to the transfer of learning; (4) their relation to repeated learning or practice; (5) their relation to thinking and the theory of thought; and (6) their relation to methodology in psychology.

The material used in this experiment consisted of the following pairs of words or syllables:

\section{SERIES $S B$}

$\begin{array}{ll}\text { 1. sauce } & \text { balloon } \\ \text { 2. mistake } & \text { clean } \\ \text { 3. elephant } & \text { steeple } \\ \text { 4. simmer } & \text { tarry } \\ \text { 5. ring } & \text { kitten } \\ \text { 6. turkey } & \text { among } \\ \text { 7. chest } & \text { muffin } \\ \text { 8. galley } & \text { time } \\ \text { 9. kimono } & \text { stencil } \\ \text { 10. space } & \text { betide }\end{array}$

SERIES $R C$

$\begin{array}{ll}\text { 1. } \text { radish } & \text { coffee } \\ \text { 2. serve } & \text { hold } \\ \text { 3. pork } & \text { cocoa } \\ \text { 4. cheese } & \text { tomato } \\ \text { 5. speak } & \text { weigh } \\ \text { 6. ribbon } & \text { banana }\end{array}$



7. being
credit
8. celery
wafer
9. troll
blast
10. soup
wall

Series $W S$
I. Wipfel
2. beharren
3. Korper
4. anregen
5. Dach
6. ereignen
7. Angriff
8. besonder
9. Citrone
10. geigen

summit

preserve

body

stimulate

roof

happen

attack

particular

lemon

fiddle

SERIES $W P$

$\begin{array}{ll}\text { 1. wum } & \text { pir } \\ \text { 2. gab } & \text { lek } \\ \text { 3. vif } & \text { gom } \\ \text { 4. mif } & \text { jas } \\ \text { 5. heb } & \text { tup } \\ \text { 6. beq } & \text { nog } \\ \text { 7. zis } & \text { ruc } \\ \text { 8. paf } & \text { zal } \\ \text { 9. dev } & \text { cux } \\ \text { 10. lir } & \text { wap }\end{array}$

The experimenter took one series at a time, read it once to the subject, and then following the prompting method, required the subject to respond with the second word of each pair as soon as possible after he gave the first word. There were 27 subjects. With the exception of nine, each subject was asked after he had learned the series to report any associations that he had formed between a given pair. The subjects of the exception were asked after every response to tell of what they had thought between the stimulus and the response. 
Before beginning the first series, the subject was instructed as follows: "I am going to read some pairs of disconnected words to you like book-ditch or feel-reply. I want you to repeat them after me the first time I read them. The second time I am going to say only the first word of each pair, and I want you to name the second word. If you don't remember it, just say 'No,' and I will prompt you. After you have learned the words, I am going to ask you to tell me whether or not you thought of anything by which you connected the pairs. For example, with book-ditch you might think of a book lying in a ditch, or just a red book, or you might have thought of nothing in particular. In that case, you just tell me that you didn't think of anything." The experimenter gave the stimulus words in the order given above except when a word was correctly responded to in a test. In that case, he skipped that word the next time he went through the series. He kept a record of every wrong reaction, of every reaction time as it was measured by a stop watch, of the number of promptings for each pair, and of every association.

The subject's retention was tested for the four series in the manner described every day for six successive days. On the sixth day three additional tests were given, the $B, D$, and $U$ tests. In the $B$ test, the subject had to learn one or two series backwards, $i$. e., name the first word of a pair after the experimenter gave the second. In the D test, the subject had to learn the first word of a series downwards, i. e., name the first word of a pair after the first word of the pair given by the experimenter. The $U$ test was just the reverse of the $\mathrm{D}$ test, e. g., when the experimenter gave the first word of the last pair, the subject had to name the first word of the pair. just before it. Verbal reports of these tests were required just as in the regular tests.

This paper will be limited to the first two problems stated above. Since the relation of associative aids to the rate of learning and of forgetting cannot be conveniently discussed 
separately, we shall discuss both of them together. By an associative aid, I understand some association that either ties the words of a pair together for the learner or ties one of them to some part of his experience. In the example given above, the thought of a 'book' lying in a ditch ties the words book and ditch together, and the thought of a red book ties the word 'book' to a part of the learner's experience.

To discover the relation of associative aids to the rate of learning and of forgetting, we might first discover how these two factors are related in themselves and afterwards hunt for a connection between this relationship and the associative aids. The relation between the rates of learning and forgetting may be discovered in three ways: (I) by seriating the average learning times, L.T.'s, of the pairs of each series for the first day of the different subjects in their order of quickness of learning and then finding the relation of the averages of the four quarters to the average L.T.'s of the corresponding quarters twenty-four hours later; (2) by setting up arbitrary limits for quickly and slowly learned pairs and then finding the relation of the L.T.'s of these pairs to the corresponding L.T.'s twenty-four hours later; (3) by setting up arbitrary limits for quickly and slowly forgotten pairs, and then finding the relation of the L.T.'s of these pairs to the L.T.'s of the corresponding pairs twenty-four hours earlier. I have followed the three methods to some extent but have made my principal calculations according to the third method.

In Table I. are presented the results according to the first method. The second and third quarters are averaged into the middle half. It will be seen that if retention is measured by the Saving Method, the old saying 'Quickly learned, quickly forgotten' is the conclusion.

The amount forgotten is in direct proportion to the quickness of learning. However, we may measure retention by the absolute length of the learning time, and in this case the amount forgotten varies inversely as the quickness of learning. To determine the relation between the rate of learning and the rate of forgetting we must first decide which is the better method of measuring retention. 
TABLE I

\begin{tabular}{|c|c|c|c|c|c|c|c|c|c|c|}
\hline & \multicolumn{5}{|c|}{ S.B. } & \multicolumn{5}{|c|}{ R.C. } \\
\hline & 急密 & 荾 & 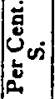 & $\dot{z}$ & $\ddot{z}$ & 焉密 & 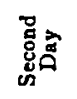 & 葋 & $\dot{z}$ & $\stackrel{\text { ș }}{z}$ \\
\hline \multirow[t]{3}{*}{$\begin{array}{l}\text { Ave. L.T. of first quarter...... } \\
\text { Ave. L.T. of mid. half....... } \\
\text { Ave. L.T. of fourth quarter... }\end{array}$} & $\begin{array}{r}3.07 \\
6.57 \\
14.16\end{array}$ & $\begin{array}{l}2.73 \\
4.18 \\
6.59\end{array}$ & $\begin{array}{l}11 \\
36 \\
53\end{array}$ & $\begin{array}{r}60 \\
130 \\
60\end{array}$ & $\begin{array}{r}6 \\
13 \\
6\end{array}$ & $\begin{array}{r}2.45 \\
4.52 \\
10.19\end{array}$ & $\begin{array}{l}2.28 \\
3.48 \\
6.21\end{array}$ & $\begin{array}{r}7 \\
23 \\
39\end{array}$ & $\begin{array}{r}50 \\
120 \\
50\end{array}$ & $\begin{array}{r}5 \\
12 \\
5\end{array}$ \\
\hline & \multicolumn{5}{|c|}{ w.s. } & \multicolumn{5}{|c|}{ W.P. } \\
\hline & 高 & 获完 & 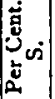 & $\dot{z}$ & $\begin{array}{l}\dot{0} \\
z \\
z\end{array}$ & 喜旁 & 葛 & 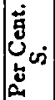 & 安 & ن \\
\hline $\begin{array}{l}\text { Ave. L.T. of first quarter..... } \\
\text { Ave. L.T. of mid. half..... } \\
\text { Ave. L.T. of fourth quarter... }\end{array}$ & $\begin{array}{r}5.49 \\
10.44 \\
19.02\end{array}$ & $\begin{array}{r}3.40 \\
5.85 \\
10.12\end{array}$ & $\begin{array}{l}38 \\
44 \\
46\end{array}$ & $\begin{array}{r}70 \\
130 \\
70\end{array}$ & $\begin{array}{r}7 \\
13 \\
7\end{array}$ & $\begin{array}{r}8.96 \\
15.59 \\
31.15\end{array}$ & $\begin{array}{r}4.97 \\
7.41 \\
12.21\end{array}$ & $\left|\begin{array}{l}44 \\
52 \\
61\end{array}\right|$ & $\begin{array}{r}70 \\
130 \\
70\end{array}$ & $\begin{array}{r}7 \\
\times 3 \\
7\end{array}$ \\
\hline
\end{tabular}

The L.T.'s are in seconds; Per cent. S. = Per cent. saved; N. = No. of pairs; N.S. $=$ No. of subjects.

The Saving Method furnishes a percentile measure of the amount of repetitions or the time saved in learning, but this does not necessarily correspond with the amount retained. Let us say that $A$ learns a stanza of poetry in 2 minutes and relearns it in $\mathrm{I}$ minute. $B$ learns the same stanza in 10 minutes and relearns it in 3 minutes. $A$ saved 50 per cent. and $B 70$ per cent. $A$ will reproduce three times as much in the same unit of time as $B$ and the entire passage in $1 / 3$ of $B$ 's time. Shall we then say that he forgot more than $B$ because he saved 20 per cent. less of his original tearning time? If $A$ forgot more than $B$, how could he reproduce three times as much in the same unit of time? If we wish to measure the efficiency of retention, it is evident that we must limit ourselves to the amount reproduced per unit of time. The same rule applies if we wish to compare the efficiency of one subject's retention with another's. In both of these cases, the Saving Method is misleading, and in every case where the learning times are not constant. Its value depends upon the amount of difference between the learning and relearning times in relation to the learning time. This value according to Table $I$. varies directly with the quickness of learning and relearning, and therefore inversely as the 
amount reproduced per unit of time in the retention test. It appears, therefore, not to be a good measure of retention. If so, the facts of Table I. mean that the rate of forgetting varies inversely as the rate of learning. But if it is doubtful what we mean by 'forgetting' or 'retention,' we can at least say that the rate of relearning varies directly with the rate of learning. From the standpoint of efficiency both statements mean the same thing, and, for our purpose, that is sufficient.

The effect of associative aids upon the relation of the rate of learning and of forgetting could be ascertained in part by finding the per cent. of the pairs for the subjects in the first quarter, middle half, and fourth quarter, respectively, that were learned by the aid of association. I have not made this calculation because of the composition of these averages which distribute the individuals only with respect to their rates of learning. But each individual has some pairs which were much more slowly learned than others, some pairs that were learned associatively, and some pairs that were learned mechanically, $i$. e., without association. The mixture of these quantitative and qualitative elements in one average destroys the true quantitative relationship between the rate of learning and of forgetting and covers up the effects of the qualitative modes of learning, $i$. e., of the associative aids. The effect of the latter is much more readily discovered if we first sort out the quickly and slowly learned pairs, as in the second method, or the quickly and slowly forgotten pairs, as in the third method.

The second and third methods are probably of equal value, but I have principally followed the third method since it was very easy to set up an arbitrary limit between quick and slow forgetting. I called those pairs slowly forgotten, S.F., which were responded to correctly in the second day without prompting, and those that required one or more promptings I called quickly forgotten, Q.F. I then averaged the L.T.'s of the first and second day for these two sorts of pairs for each subject, then seriated the subjects in their order of quickness of learning for the first day for each sort of pairs, 
and found the averages for the first quarter, the middle half, and the fourth quarter, respectively, as in the first method. The results for the four series appear in Table II., which also contains the percentile values of retention, the number of pairs, and the number of subjects for each quarter or half.

Table II. shows that the S.F. pairs, those responded to correctly on the second day without prompting, were quickly learned on the first day, i. e., that quick relearning is accompanied by quick learning. This is evident from a comparison of the L.T.'s of the Q.F. and S.F. pairs, quarter for quarter and half for half for each series. With a few exceptions, we can again say that the rate of relearning varies directly as the rate of learning, also that retention as measured by the Saving Method varies directly as the length of the learning time for both Q.F. and S.F. pairs, and for each kind of material. But the striking fact is that quarter for quarter and half for half the retention for the S.F. pairs is invariably higher than for the Q.F. pairs. Whether we measure retention by the Saving Method or by the length of the learning time, it is higher in every case for the quickly learned than for the slowly learned pairs. The old saying 'Quickly learned, quickly forgotten' must therefore be changed into 'Quickly learned, slowly forgotten.' This relationship is also affected by the quality of the material. The often repeated statement that meaningful material is forgotten more slowly than nonsense material must be qualified in several ways: First, with respect to the Q.F. pairs, the more meaningful material, the more rapid the forgetting; second, with respect to the S.F. pairs, the more meaningful the material, the slower the forgetting. These statements are based on the average per cent. S. for the Q.F. and S.F. pairs of each series.

We are now in position to state the relation of associative aids to the rate of learning and forgetting. This was determined by calculating the number and the per cent. of Q.F. pairs and of S.F. pairs that were learned with an association on the first and second days, respectively. The results are given in Table III. In this table, we notice first the large differences between the Q.F. and S.F. pairs that were learned 
TABLE II

\begin{tabular}{|c|c|c|c|c|c|c|c|c|c|c|c|c|c|c|c|c|c|c|c|c|}
\hline & \multicolumn{10}{|c|}{$s^{\circ} B}$. & \multicolumn{10}{|c|}{ R.C. } \\
\hline & \multicolumn{5}{|c|}{ Q.F. } & \multicolumn{5}{|c|}{ S.F. } & \multicolumn{5}{|c|}{ Q.F. } & \multicolumn{5}{|c|}{ S.F. } \\
\hline & 蒙言 & 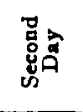 & 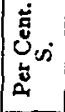 & $\dot{z}$ & $\begin{array}{l}\dot{\varphi} \\
\dot{z}\end{array}$ & 总密 & ڤ్ & 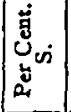 & 2 & पृ & 高 & 遌 & $\mid \begin{array}{l}\dot{j} \\
\tilde{u}_{\infty}^{\infty} \\
y^{\infty}\end{array}$ & $\dot{z}$ & $\begin{array}{l}\dot{0} \\
\dot{z}\end{array}$ & 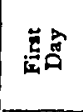 & 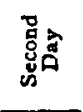 & $\mid \begin{array}{l}\vec{j} \\
\dot{u} \\
\Delta\end{array}$ & $\dot{z}$ & on \\
\hline $\begin{array}{l}\text { Ave L.T. of first quarter } \ldots \\
\text { Ave L.T. of mid. half . . . } \\
\text { Ave L.T. of fourth quarter.. } \\
\text { Ave. L.T. of all. . . . . . }\end{array}$ & $\begin{array}{r}3.40 \\
8.47 \\
15.03 \\
8.86 \\
\end{array}$ & $\begin{array}{r}6.23 \\
14.07 \\
8.17 \\
7.43 \\
\end{array}$ & $\begin{array}{r}-81 \\
-66 \\
45 \\
16 \\
\end{array}$ & $\begin{array}{r}26 \\
48 \\
27 \\
101 \\
\end{array}$ & $\begin{array}{r}6 \\
11 \\
6 \\
23\end{array}$ & $\begin{array}{l}2.06 \\
4.23 \\
9.47 \\
4.99 \\
\end{array}$ & $\begin{array}{l}2.43 \\
2.20 \\
2.37 \\
2.30\end{array}$ & $\begin{array}{r}-13 \\
48 \\
72 \\
54 \\
\end{array}$ & $\begin{array}{r}37 \\
71 \\
41 \\
141 \\
\end{array}$ & $\begin{array}{r}6 \\
11 \\
6 \\
23 \\
\end{array}$ & $\begin{array}{r}2.05 \\
5.58 \\
14.56 \\
6.94 \\
\end{array}$ & $\begin{array}{l}5.01 \\
5.64 \\
5.76 \\
5.52 \\
\end{array}$ & $\begin{array}{r}-144 \\
-1 \\
60 \\
20 \\
\end{array}$ & $\begin{array}{l}11 \\
42 \\
18 \\
71\end{array}$ & $\begin{array}{r}5 \\
11 \\
5 \\
21 \\
\end{array}$ & $\begin{array}{l}2.27 \\
4.31 \\
8.84 \\
4.90 \\
\end{array}$ & $\begin{array}{l}2.18 \\
2.22 \\
3.32 \\
2.38 \\
\end{array}$ & $\begin{array}{r}4 \\
48 \\
62 \\
51 \\
\end{array}$ & $\begin{array}{r}31 \\
82 \\
36 \\
149 \\
\end{array}$ & $\begin{array}{r}5 \\
11 \\
5 \\
21\end{array}$ \\
\hline \multirow[t]{2}{*}{ A.D. . . . . . . . . . . } & 3.72 & 2.50 & & & & 2.22 & .91 & & & & 2.17 & 2.29 & & & & 2.11 & .72 & & & \\
\hline & \multicolumn{10}{|c|}{ w.s. } & \multicolumn{10}{|c|}{ W.P. } \\
\hline $\begin{array}{l}\text { Ave. L.T. of first quarter. . } \\
\text { Ave. I.T. of mid. half. . } \\
\text { Ave. L.T. of second quarter } \\
\text { Ave. L.T. of all . . . . . }\end{array}$ & $\begin{array}{r}6.01 \\
14.06 \\
22.95 \\
14.43 \\
\end{array}$ & $\begin{array}{r}5.38 \\
10.75 \\
12.50 \\
9.83 \\
\end{array}$ & $\begin{array}{l}10 \\
23 \\
4 \mathrm{I} \\
32 \\
\end{array}$ & $\begin{array}{r}35 \\
62 \\
42 \\
139 \\
\end{array}$ & $\begin{array}{r}7 \\
13 \\
7 \\
27 \\
\end{array}$ & $\begin{array}{r}1.78 \\
4.83 \\
11.35 \\
5.76 \\
\end{array}$ & $\begin{array}{l}1.67 \\
1.79 \\
2.26 \\
1.87 \\
\end{array}$ & $\begin{array}{r}6 \\
63 \\
71 \\
67 \\
\end{array}$ & $\begin{array}{r}34 \\
56 \\
36 \\
126 \\
\end{array}$ & $\left\{\begin{array}{r}7 \\
13 \\
7 \\
27 \\
\end{array}\right.$ & $\begin{array}{r}9.54 \\
17.06 \\
33.69 \\
19.42 \\
\end{array}$ & $\begin{array}{r}6.00 \\
9.90 \\
16.15 \\
10.56\end{array}$ & $\begin{array}{r}37 \\
42 \\
52 \\
451 \\
\end{array}$ & $\begin{array}{l}46 \\
85 \\
49 \\
80 \\
\end{array}$ & $\begin{array}{r}7 \\
13 \\
7 \\
27 \\
\end{array}$ & $\begin{array}{r}4.93 \\
13.50 \\
27.87 \\
14.88\end{array}$ & $\begin{array}{l}1.79 \\
4.85 \\
2.93 \\
2.68\end{array}$ & $\begin{array}{l}63 \\
65 \\
89 \\
82\end{array}$ & $\begin{array}{l}16 \\
56 \\
16 \\
88 \\
\end{array}$ & $\begin{array}{r}6 \\
13 \\
6 \\
25 \\
\end{array}$ \\
\hline A.D. $\ldots \ldots \ldots$ & 4.92 & 5.17 & & & & 3.40 & .43 & & & & 7.65 & 4.58 & & & & 6.88 & .96 & & & \\
\hline
\end{tabular}

Q.F. = Quickly forgotten pairs.

S.F. = Slowly forgotten pairs. 
TABLE III

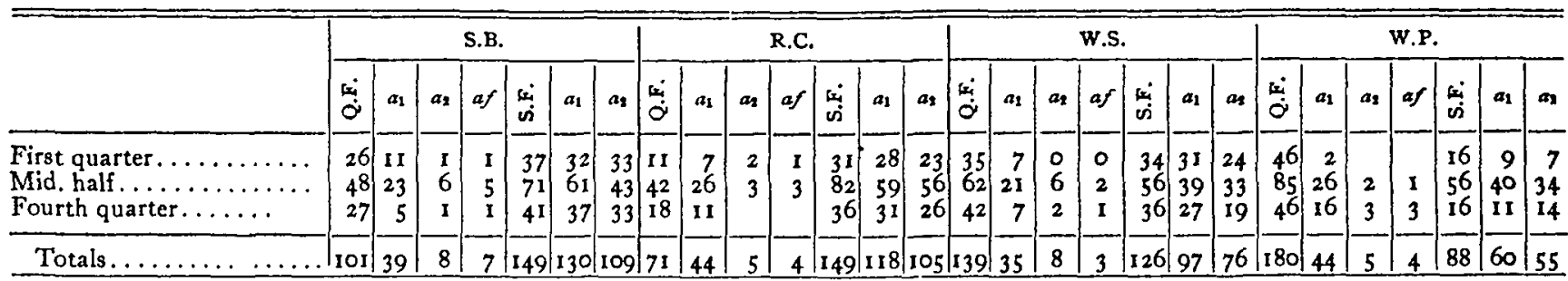

$a_{1}$ and $a_{2}$ Expressed in Percentages

\begin{tabular}{|c|c|c|c|c|c|c|c|c|c|c|c|c|c|c|c|c|c|c|c|c|c|c|c|c|c|c|c|c|}
\hline & $\stackrel{\dot{\alpha}}{\dot{\alpha}}$ & $a_{1}$ & $a_{1}$ & af & 离 & $a_{1}$ & $a_{2}$ & $\stackrel{4}{0}$ & $a_{1}$ & $a_{2}$ & af & $\left\{\begin{array}{l}\dot{a} \\
\dot{\omega}\end{array}\right.$ & $a_{1}$ & $a$ & $\dot{\alpha}$ & $a_{1}$ & $a_{3}$ & $a f$ & ci & $a_{1}$ & $a_{2}$ & $\mid \begin{array}{c}\dot{4} \\
\dot{\alpha}\end{array}$ & $a_{1} \mid$ & $a_{2}$ & of & 占 & $a_{1}$ & $a_{2}$ \\
\hline $\begin{array}{l}\text { First quarter. } \\
\text { Mid. half.. } \\
\text { Fourth quarter. }\end{array}$ & $\begin{array}{l}26 \\
48 \\
27\end{array}$ & $\begin{array}{l}42 \\
48 \\
19\end{array}$ & $\begin{array}{r}4 \\
12 \\
4\end{array}$ & $\begin{array}{r}4 \\
10 \\
4\end{array}$ & $\begin{array}{l}37 \\
71 \\
41\end{array}$ & $\left|\begin{array}{l}87 \\
86 \\
90\end{array}\right|$ & $\begin{array}{l}89 \\
60 \\
80\end{array}$ & $\begin{array}{l}11 \\
42 \\
18\end{array}$ & $\begin{array}{l}64 \\
62 \\
61\end{array}$ & $\begin{array}{r}19 \\
7\end{array}$ & $\begin{array}{l}9 \\
7\end{array}$ & $\begin{array}{l}31 \\
82 \\
36\end{array}$ & $\begin{array}{l}90 \\
72 \\
86\end{array}$ & $\begin{array}{l}74 \\
68 \\
58\end{array}$ & $\begin{array}{l}35 \\
62 \\
42\end{array}$ & $\begin{array}{l}20 \\
34 \\
17\end{array}$ & $\begin{array}{l}9 \\
5\end{array}$ & $\begin{array}{l}3 \\
2\end{array}$ & & $\begin{array}{l}91 \\
70 \\
75\end{array}$ & $\begin{array}{l}71 \\
59 \\
53\end{array}$ & $\begin{array}{l}46 \\
48 \\
49\end{array}$ & $\begin{array}{r}2 \\
31 \\
33\end{array}$ & $\begin{array}{l}2 \\
6\end{array}$ & $\begin{array}{l}1 \\
6\end{array}$ & $\begin{array}{l}16 \\
56 \\
16\end{array}$ & $\begin{array}{l}56 \\
71 \\
69\end{array}$ & $\begin{array}{l}44 \\
61 \\
87\end{array}$ \\
\hline Tota & $|\mathrm{ror}|$ & 39 & 8 & 7 & 149 & $\mid 87$ & 76 & $\sqrt{71}$ & 62 & 7 & 6 & $\mid 149$ & 79 & 70 & $\mid 139$ & 25 & 6 & 2 & $|126|$ & 77 & 60 & 180 & 24 & 3 & 2 & 88 & 68 & 62 \\
\hline
\end{tabular}

$a_{1}=$ No, of associative aids, first day.

$a_{2}=$ No. of asociative aids, second day.

af $=$ No, of associative aids working falsely on second day.

Under Q.F. and S.F. are stated the number of pairs in each quarter or half. 
TABLE IV

\begin{tabular}{|c|c|c|}
\hline General average L.T. first day & $\underset{12.41}{Q . F}$ & $\begin{array}{l}\text { S.F. } \\
7.63\end{array}$ \\
\hline General average L.T. second day. & 8.34 & 2.31 \\
\hline Per cent. saved. & 32 & 69 \\
\hline Number of subjects $\ldots \ldots \ldots \ldots \ldots \ldots \ldots$ & 27 & 27 \\
\hline Number of pairs. . . . . . . . . . . . . . . . & 491 & 512 \\
\hline Per cent. of pairs with $A_{1} \ldots \ldots, \ldots \ldots \ldots$ & 33 & 79 \\
\hline Per cent, of pairs with $A_{2} \ldots \ldots, \ldots \ldots \ldots$ & 5 & 67 \\
\hline Per cent. of pairs with $A f \ldots \ldots \ldots \ldots \ldots \ldots$ & 4 & o \\
\hline
\end{tabular}

with associative aids on the first day. The per cent. varies from 39 to 62 for the Q.F. pairs and from 68 to 87 for the S.F. pairs. Second, we notice that on the second day most of the associative aids for the Q.F. pairs are forgotten and nearly all of those that are not forgotten produce a false response; but most of the associative aids for the S.F. pairs are remembered. The per cent. of the associative pairs for the Q.F. pairs remembered varies from 3 to 8 , and from 2 to 7 per cent. of them produce false responses. But the per cent. of associative aids for the S.F. varies from 60 to 76. The meaning of these facts is quite clear, but it may be made still more clear by a study of the general averages, totals, and per cents. in Table IV.

In Table IV. I wish to draw attention to the much smaller L.T.'s for the S.F. pairs, then to their much greater retention, then to the approximately equal number of Q.F. and S.F. pairs, then to the fact that more than twice as many of the S.F. pairs are learned with associative aids on the first day and more than 13 times as many of them are learned on the second day, and finally to the fact that four fifths of the associative aids for the Q.F. pairs remembered on the second day produce false responses. I believe that these facts establish a causal relation between the rate of learning and forgetting on the one hand, and associative aids on the other hand. This is confirmed positively by the high frequency of the latter in the S.F. pairs, and negatively by their low frequency in the Q.F. pairs. We also see that although the Q.F. and S.F. pairs are learned in qualitatively different ways, yet this qualitative difference is stateable in quantitative terms in the number of associations. 
Confirmation of the above conclusions as well as suggestive evidence of why there is not a Ioo per cent. frequency of associative aids in the S.F. pairs is obtained by calculating the number of promptings, R., required to learn the Q.F. and S.F. pairs as this is influenced by the presence and absence of associative aids. The results are given in Table V. From this we see that the presence of associative aids

TABLE V

\begin{tabular}{ll|c|c|c|c}
\hline \hline & S.B & R.C. & W.S. & W.P. \\
\hline Ave. No. of R. for Q.F. pairs with associations . . . & 2.14 & 1.78 & 2.58 & 3.56 \\
Ave. No. of R. for Q.F. pairs without associations . . & 3.15 & 2.48 & 3.57 & 4.92 \\
Ave. No. of R. for S.F. pairs with associations . . . . & 1.51 & 1.44 & 1.65 & 2.93 \\
Ave. No. of R. for S.F. pairs without associations $\ldots$ & 2.42 & 1.92 & 2.84 & 4.66 \\
\hline
\end{tabular}

makes a considerable reduction of the number of prompting in both the Q.F. and the S.F. pairs, that is, they make learning easier. The greater number of promptings for the S.F. pairs without association suggest that high retention may be due to strong imprinting as well as the presence of an association. Because of this factor we would not expect a 100 per cent. frequency of associative aids in the S.F. pairs or 100 per cent. absence in the Q.F. pairs.

Having stated the general principles about the relation of associative aids to the rate of learning and of forgetting, it may be well to reproduce a few of the original records as illustrations both of the rules and of the possibility of treating the data statistically.

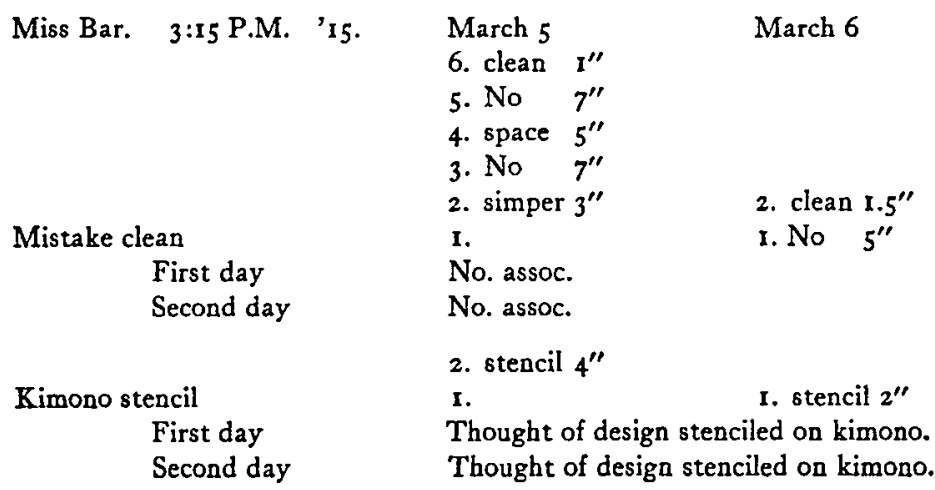


Miss Hill. 5 P.M.

Cheese tomato

First day

Second day

Troll blast

First day

Second day

Miss Bar. 3:15 ' 15 .

Angriff attack

First day

Second day

Citrone lemon

First day

Second day

Miss Boss. 4 P.M., '15

Vif gom

I.

2. blast 2.6"

I.

No assoc.

No assoc.

March 5

4. attack $4^{\prime \prime}$

3. No $5^{\prime \prime}$

2. No 6.5"

I.

No assoc.

No assoc.

2. lemon 2.5"

I.

Thought of something sour and a response to 2 three-syllable word.

Same as yesterday.

May 25

May 26

3. gom $6^{\prime \prime}$

2. niff $5^{\prime \prime}$

1. lif $5^{\prime \prime}$

First day.......... Thought of folks chewing gum and coming down with wif.

Second day.......... Nothing before first two promptings and then I thought of some one's mouth coming down with a vif in chewing gum.

4. ruc 7.4"

3. No. $6^{\prime \prime}$

2. jog 4."

Zis ruc

First day

$$
\text { I. }
$$

I. ruc $4^{\prime \prime}$

Second day

Thought of seeing the rock.

Thought of seeing the rock.

The above examples give the number of promptings, responses, and L.T.'s, and associative aids, if any, for the pairs and subjects named for the first and second days. The first prompting, I, opposite the pair was the reading of the pair by the experimenter and had no response. Above it are the results of the second, third, and fourth prompting, as the case may be. Under the line containing the wordpair are described the associations if any for that pair, and 
the date of the same. The individual records are of course not as regular as the averages but nevertheless show the rule.

It will now be in place to discuss the experiments of other investigators whose results bear upon the conclusions stated above. The first experimental results bearing upon the relation between the rate of learning and of forgetting were obtained by Müller and Schumann. They are given by Ebbinghaus, 'Grundriss,' I., p. 682, and are directly in agreement with the results of Table I., showing that the number of repetitions in relearning and the per cent. S. vary directly with the number of repetitions in learning. The conclusion drawn was that slow learners forget slowly. But we have seen that this depends altogether upon how we measure retention.

Following Müller and Schumann, Meumann made some experiments which he says justify the same rule. He does not give his data, but explains the relationship in terms of the adaptability of the learner's attention, his purpose or adjustment, his imagery and method of learning. The slow learner has fixed attention, steady purpose, visual imagery, and makes little use of secondary characteristics in the impressions. The quick learner has a highly adaptable attention, temporary purposes, auditory imagery, and makes use of secondary means, such as "special auditory and visual remembrances derived from non-essential circumstances which attend the learning." He states that the more extensively we use the latter, the more transient is attention. This is just the opposite of our experimental results, and since Meumann does not give the facts for his statement, I shall make no further answer. I have made no extended study of the type of imagery upon learning, but some of my most rapid learners were so-called visual learners and some of my slowest learners were so-called auditory learners. The associations of the former were such as: "I saw the words" or "I saw the objects." The associations of the latter were such as: "I thought of corporal for "Körper-body." On the other hand I have evidence which apparently confirms Meumann's state-

I'Psychology of Learning,' tr. by Baird, p. 177. 
ments on the type of imagery. My own observations lead me to believe that the rate of learning depends upon something much more fundamental than the type of imagery, namely, inherited ability and association. I should agree that the rapid learner has a more adaptable attention than the slow learner, but it is not usually concomitant with rapid forgetting.

Balaban ${ }^{1}$ obtained some interesting results upon the influence of association upon the rate of learning and of forgetting. His subjects learned series of 20 unrelated wordpairs. They were instructed to learn one half of them logically and the other half mechanically. To test the influence of these words upon learning, the series were presented once and then tested by the Treffer Method. The logically learned series gave an average of 33.9 successes, and the mechanically learned series an average of 7.9 successes. To test the influence upon retention, the series were completely learned and tested after intervals of 3 and 6 days. Subject I. learned the logical series in 3 repetitions and had 3.3 successes. Subject II. gave similar results. Although the associations in this experiment were largely voluntary, whereas in mine they were largely involuntary and spontaneous, the results of both lead to the same conclusions.

Busemann ${ }^{2}$ made groups tests on school children by the Treffer Method by reading to them four series having eight pairs of words from each of the following: concrete nouns, abstract nouns, adjectives, verbs, and meaningless words. The per cent. of successes for each of these were $80.5,70$, $51.7,49.2$, and 14 , respectively. For 6 subjects who followed the method of complete learning, the results were:

\begin{tabular}{|c|c|c|c|}
\hline & Nouns & Adjectuves & Syllabies \\
\hline 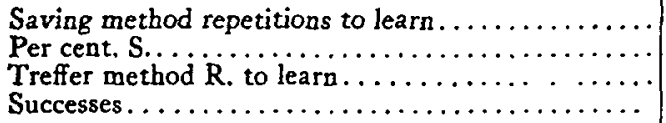 & $\begin{array}{l}8.5 \\
64 \\
10.5 \\
6.5\end{array}$ & $\begin{array}{l}11.0 \\
57 \\
15.1 \\
55\end{array}$ & $\begin{array}{l}13 \\
61 \\
22 \\
4 I\end{array}$ \\
\hline
\end{tabular}

1 Zeit. f. Psychol., 56, 1910, $356 \mathrm{ff}$.

ZZit. f. Angew. Psychol., V, Igr r, 211 ff. 
Busemann investigated the frequency of associative aids in one subject and found the following: nouns 88 per cent.; adjectives 57 per cent.; and syllables 54 per cent. It will be seen that this experiment in every way confirms the results and conclusions of the present experiment.

G. E. Müller ${ }^{1}$ made a study of associative aids in connection with the remarkable memory of Dr. Rückle, who had a memory-span for 72 numbers, and found that he made use of many ingenious aids that would not occur to an ordinary person. For example:

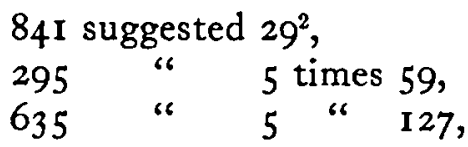

and that 127 is characteristic since it is the first prime number after II3. 535 suggested .535 , the side of a circumscribed polygon. 548519 suggested that the difference between the first and the second halves is the prime number 29. 70128 suggested 701 plus $28=729=9^{8}$. 901 suggested the year in which the Queen of Saxony came to the throne. Müller, after a careful study of these associations, concludes that he is justified in setting up as a general law that exceptional memory performances of this sort are conditioned by the coöperation of natural helps in so far as they do not rest upon mnemonic devices (p. 236). After reviewing the results of the experiments of Balaban, Busemann, Michotte and Ransy, and Ephrussi bearing upon associative aids, he notices that they shorten the learning time, heighten retention, and shorten the reaction time, and concludes that they have the advantage of strengthening the connections between members and of facilitating the transitions between complexes. On the other hand, they have the disadvantage of sometimes diverting the attention from the associated members and of leading to a reproduction of the aid instead of the associated members. ${ }^{2}$ So far as my experiment goes, I have no grounds for dissent from G. E. Müller. If spontaneous verbal associations lower the learning time and heighten the retention of

1 Zeit. f. Psychol. Erg-Bd., 5, 1911.

- Zeit. f. Psychol. Erg-Bd., 8, 1913. 
verbal material, it would be the same psychological result if mathematical association of Rückle's type should increase the memory-span for numbers, facilitate rapid calculation, and produce high retention for numbers.

Among American investigators who made experiments, the results of which bear upon the relation between the rate of learning and of forgetting, are Whitehead, Henderson, Ogden, Pyle, Norsworthy, Woodworth, and Lyon. Whitehead studied the effect of visual and auditory modes of presentation upon learning and retention, but with regard to the rate of learning he concludes that the slow learner relearns in a shorter time and retains a larger amount than the fast learner. But Pyle, who recalculated his data after eliminating the results of one S. as erroneous, finds by adding the L.T.'s of the fast six and of the slow six that the six who learned in the shortest time also relearned in the shortest time. ${ }^{1}$ Henderson, who had subjects read twice a selection from Irving's 'Dutch Homestead' and then had them write down what they could remember after zero, two-day, and four-week intervals, found that the quick learner recalled greater percentages of what they had learned than the slow learners. Ogden, ${ }^{2}$ who studied the influence of the rate of reading upon learning and retention, found that the fast learners usually require less time for relearning than the slow ones, and that this is true both for meaningful and nonsense material. Pyle, ${ }^{3}$ who had college students memorize 40 items from a book on nature study and relearn them after 24 hours, found that the quickest of four subjects learned the material in 4.I repetitions and reproduced 38.5 ideas; and that the slowest required 4.7 repetitions and reproduced 37.5 ideas. Two other groups of four subjects each yielded similar results. From 6 subjects who learned series of 25 nonsense syllables forward by the method of daily repeated learning until permanent retention was obtained, and then learned them backwards by the same method, he found that the total number of repetitions required for permanent reten-

${ }^{1}$ Summarized from Lyon, Arch. of Psychol., 1916, No. 34 .

'Arch.f.d. ges. Psychol, 1904, 2, 93 ff.

8J. of Educ. Psychol., 1913, 2, $310 \mathrm{ff}$. 
tion in each case was in proportion to the number of repetitions required to learn the series on the first day. According to Lyon, ${ }^{1}$ Gamble, who read series of letters, words, and figures to 350 college students and then tested retention by the amounts which they could reproduce after one, two, and five(?) readings, respectively, found a marked correlation between facility in learning and relearning. In her recently reported study ${ }^{2}$ of the effect of the rate of repetition on learning and retention, she finds no proof that rapidly repeated series are forgotten more rapidly than slowly repeated series. Her materials consisted entirely of nonsense syllables. Norsworthy ${ }^{3}$, who had 83 college students study a list of $\mathrm{I}, 200$ German-English vocabularies 20 minutes a day, 5 days a week, for three weeks and tested retention with selected lists of 50 German words at intervals of 2 days and of 30 days after the third week of study, found that the fastest half of the learners remembered 70 per cent. of the words in the first test and 73 per cent. in the second test. The slowest half remembered only $5^{2}$ per cent. in the first test and 47 per cent. in the second test. Those who learned over 900 words within the limits of time for study remembered 76 per cent. in the first test and 78 per cent. in the second test, and those learning less than 300 words within the same time remembered 46 per cent. in the first test and 36 per cent. in the second test. The most extensive study upon the problem in question was made by Lyon, ${ }^{4}$ who obtained results from 426 subjects, all being adults except 40 . His materials for the most part consisted of series of 20 digits, series of 20 nonsense syllables, a series of 20 unrelated 3 -letter words, a passage of prose having 100 words, and a passage of poetry having four 4 -line stanzas. All of the materials were completely learned, and retention was tested after various intervals first by the amount which the subject could reproduce without a repetition, Method $\mathrm{I}$, second by the amount which the subject could reproduce after one repetition,

i Op. cit., p. ro.

2 Psychol. Monog., 1916, No. 96, p. $99 \mathrm{ff}$.

'J. of Educ. Psychol., I913, 4, 61 ff.

Op. cit. 
Method 2, and third by the Saving Method, for which the material was completely learned immediately after Method 2 was finished. Since his material may be roughly divided into meaningful (prose and poetry) and meaningless (all the rest), I shall give sample results of each kind from Table XI. for 24 normal college seniors:

Nonsense SyLlables

\begin{tabular}{|c|c|c|c|c|c|}
\hline & L.T. & Rl.T. & Per Cent. S. & Meth. I & Meth. 2 \\
\hline $\begin{array}{l}\text { Upper half } \ldots \ldots \ldots \ldots \ldots \ldots \ldots \\
\text { Lower half... } \ldots \ldots \ldots \ldots \ldots \ldots\end{array}$ & $\begin{array}{r}5.5^{\prime} \\
15.0^{\prime} \\
\end{array}$ & $\begin{array}{r}6.5^{\prime} \\
12.1^{\prime} \\
\end{array}$ & $\begin{array}{l}71 \\
68 \\
\end{array}$ & $\begin{array}{l}26 \\
21\end{array}$ & $\begin{array}{l}44 \\
36 \\
\end{array}$ \\
\hline
\end{tabular}

Prose

\begin{tabular}{l|l|l|l|l|l}
\hline Upper half $\ldots \ldots \ldots \ldots \ldots \ldots \ldots$ & $14 \cdot 3^{\prime}$ & $\begin{array}{l}4.8^{\prime} \\
\mathbf{2 7} \cdot 3^{\prime}\end{array}$ & 68 & 56 & 80 \\
Lower half $\ldots \ldots \ldots \ldots \ldots \ldots \ldots$ & $\mathbf{2 7} \mathbf{1}^{\prime}$ & 66 & $4^{6}$ & 67 \\
\hline
\end{tabular}

Average for All Material

\begin{tabular}{ll|l|l|l|l|l|l}
\hline Upper half. ....... & $\ldots \ldots \ldots \ldots$ & $12.2^{\prime}$ & $4 \cdot 3^{\prime}$ & 61 & 39 & 55 \\
Lower half... & $\ldots \ldots \ldots \ldots \ldots$ & $21.9^{\prime}$ & $7 \cdot 2^{\prime}$ & 66 & 30 & $4^{6}$ \\
\hline
\end{tabular}

Interval between L.T. and RI.T. is one week for meaningless material and ten weeks for meaningful. From these and other results, Lyon concludes that "the most general statement that can be made is that those who learn quickly remember longest if the material is logical in character. Where the material is 'illogical' and is meaningful by 'motor associations,' so to speak, the converse is true. This, however, has many exceptions, depending upon the method used" (p. 58). From his study of the merits and demerits of the different methods of measuring retention, he concludes: "The different methods give opposite results, and yet in one sense of the word, one method is as 'correct' as another" (p. 56).

Whatever the value of the different methods used by Lyon may be, it is clear from the above results that the quick learners relearn more quickly and reproduce absolutely greater amounts than the slow learners. If a quick learner relearns his lesson more quickly and reproduces more of it than a slow one, it makes little difference from the standpoint of efficiency what the Saving Method tells us about his 'retention.' I ask again, how can a slow learner remember more 
than a quick one when he reproduces less, or how can he forget more slowly when he has a longer relearning time? The lengths of the relearning times as well as of the corresponding results of Methods $I$ and 2 clearly show the invalidity of the Saving Method as a measure of forgetting. If we accept this, then we must admit that Lyon's conclusions are at variance with his facts which really support the conclusion that I have drawn from my own data. Lyon's statement of his data, however, is similar to the one that I have used in Table I. We have seen that that method is not well adapted for solving the problem in question. If Lyon could have separated the associatively learned materials from the mechanically learned materials, he would have had little difficulty in solving his problem. In this connection, we notice his conclusion regarding logical material which is quickly learned and slowly forgotten. Is this because of the character of the material or is it because the prose is usually learned by a different psychological process than are nonsense syllables? We noticed from our results that the character of the material is of little importance in determining the relationship between the rates of learning and forgetting in comparison to the way in which that material is learned psychologically. Meaningful material differs from meaningless only in having a greater number of associative aids, and it is those which make possible Lyon's conclusions regarding logical material.

From this review of the facts of the American investigators, only one conclusion is possible, namely, that quick learning means quick relearning. To my mind this is the same as saying that quick learning means slow forgetting. But wherefore this relationship? It appears that none of the above named investigators considered this question, nor was its answer made possible by their methods which lacked the qualitative side. We have seen, however, that the study of associative aids has furnished a reliable solution.

\section{SUMmary I.}

The relation of the rate of learning to the rate of forgetting depends upon three conditions: (I) the character of the 
measure; (2) the character of the learning; and (3) the character of the material. If the Saving Method is the measure of retention, then "Quickly learned, quickly forgotten" expresses the relation. If the amount reproduced per unit of time is the measure, then "Quickly learned, slowly forgotten" is true. The Saving Method is, however, a false measure of retention, for it does not express the efficiency of memory. This leaves only the second statement as true, which may be more accurately expressed as follows: the rate of relearning varies directly as the rate of learning, or the rate of forgetting varies inversely as the rate of learning.

The cause of this relationship is found in the character of the learning as shown in the influence of associative aids. Word pairs are quickly learned and slowly forgotten by means of associative aids. The absence of these associates produces slow learning and quick forgetting.

The influence of the character of the material may be stated as follows: For quickly forgotten pairs, the more meaningful the material, the more rapid the forgetting. For slowly forgotten pairs, the more meaningful the material the slower the forgetting.

A review of the literature upon the rate of learning and of forgetting shows that the facts of other investigators support the conclusion stated above, but they drew opposite conclusions because of an uncritical interpretation of the measure of retention.

\section{II}

If associative aids are of such great importance in determining the rate of learning and of forgetting, it will be a matter of interest to study them analytically and find their relation to other associations. Analytic studies of associative aids have been made by Ephrussi, Balaban, Busemann, and G. E. Müller. Since such a study and the resulting classification are matters of interpretation rather than of fact, I shall give no account of the classifications made by these investigators. I have largely followed the demands of my materials, and, so far as possible, have adopted the usual categories for this purpose. 
Since the material of the experiment consisted of paired associates, it is possible that such an association should be connected with (I) both words, the stimulus and the response, or (2) with the first word only, the stimulus, or (3) with the second word only, the response. The associative aids were accordingly distributed with reference to these situations. The next step in the classification was to distribute the associative aids of each class with reference to their most outstanding relationship to each situation. In naming this relationship, no account was taken of the learner's opinion, nor was such an opinion asked. The subject having reported the association, it was treated as so much matter to be classified with respect to such relationship as the experimenter could find between it and the situations with which it was connected. These relationships, therefore, do not tell us what psychological factors produce these associations, but only give us some ground for a further inference as to what these factors might be, and on the theory of probability help us to predict their recurrence in the future under similar circumstances. Since a classification of associations with respect to two words is rather unusual, the following table of categories will give examples:

Associations of

\begin{tabular}{|c|c|c|c|}
\hline $\begin{array}{l}\text { Similarity in } \\
\text { sound or } \\
\text { sight of }\end{array}$ & $\left\{\begin{array}{l}\text { Letters } \\
\text { Syllables } \\
\text { Rhythm }\end{array}\right.$ & $\begin{array}{l}\text { Zis ruc } \\
\text { Mistake clean } \\
\text { Heb tup }\end{array}$ & $\begin{array}{l}\text { ' } \mathrm{Z}-\mathrm{R} \text { ' } \\
\text { 'Take lean' } \\
\text { 'Head top' }\end{array}$ \\
\hline & Contrast & Chest muffin & $\begin{array}{l}\text { 'The one is large and the other is } \\
\text { small.' }\end{array}$ \\
\hline $\begin{array}{r}\text { Similarity in } \\
\text { meaning of }\end{array}$ & $\begin{array}{l}\text { Verbal Habit } \\
\text { Coördination } \\
\text { Predication } \\
\text { Adjectival }\end{array}$ & $\begin{array}{l}\text { Korper body } \\
\text { Celery wafer } \\
\text { Simmer tarry } \\
\text { Mistake clean }\end{array}$ & $\begin{array}{l}\text { 'Corpus body' } \\
\text { 'Lettuce and crackers.' } \\
\text { 'Both slow.' } \\
\text { 'Clean mistake.' }\end{array}$ \\
\hline
\end{tabular}

\begin{tabular}{|c|c|c|c|}
\hline $\begin{array}{l}\text { Thoughts of } \\
\text { patterns like }\end{array}$ & Words & $\begin{array}{l}\text { Simmer tarry } \\
\text { Ring kitten }\end{array}$ & 'Cemetery.' \\
\hline & $\begin{array}{l}\text { Words only } \\
\text { Objects only }\end{array}$ & $\begin{array}{l}\text { Troll blast } \\
\text { Ribbon banana }\end{array}$ & $\begin{array}{l}\text { 'Saw the words.' } \\
\text { 'A pink ribbon beside a banana.' } \\
\text { 'Saw the words and the obiects,' }\end{array}$ \\
\hline$x$ & $\begin{array}{l}\text { Order and } \\
\text { position }\end{array}$ & Geigen fiddle & 'Last pair.' \\
\hline & Time & $\operatorname{mif}$ jas & 'Third one I missed.' \\
\hline
\end{tabular}


Table VI

\begin{tabular}{|c|c|c|c|c|c|c|c|c|c|c|c|c|c|c|c|c|}
\hline \multirow{4}{*}{ Conpected with } & \multicolumn{15}{|c|}{ Per Cent. of Associative Aids Consisting of } & \multirow{4}{*}{ 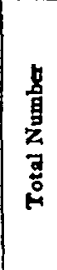 } \\
\hline & \multicolumn{8}{|c|}{ Familiar Words or Phrases Similar as to } & \multicolumn{5}{|c|}{ Thoughts of } & \multirow{2}{*}{\multicolumn{2}{|c|}{$\begin{array}{c}\text { Associations of } \\
\text { Contiguity in }\end{array}$}} & \\
\hline & \multicolumn{3}{|c|}{ Sound or Sight of } & \multicolumn{5}{|c|}{ Meaning in } & \multicolumn{2}{|c|}{ Patterns Like } & \multirow[b]{2}{*}{$\begin{array}{l}\text { चै } \\
\text { है } \\
\frac{2}{5}\end{array}$} & \multirow[b]{2}{*}{$\begin{array}{l}\stackrel{8}{8} \\
0 \\
0 \\
\overline{8}\end{array}$} & \multirow[b]{2}{*}{ 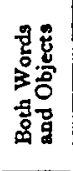 } & & & \\
\hline & $\stackrel{5}{5}$ & 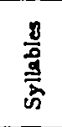 & 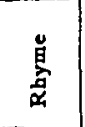 & $\begin{array}{l}\ddot{g} \\
\dot{5} \\
\dot{0}\end{array}$ & 疍突 & 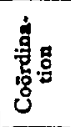 & 鴶点 & 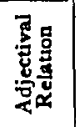 & है & 总 & & & & 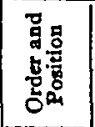 & 惫 & \\
\hline 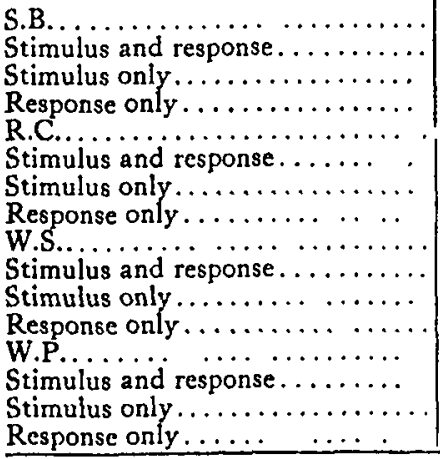 & 1.88 & $\begin{array}{l}.27 \\
.27 \\
.54\end{array}$ & $\begin{array}{r}3.48 \\
.87 \\
16.32 \\
1.90 \\
.54 \\
28.20 \\
2.63 \\
11.28 \\
\end{array}$ & 1.63 & $\begin{array}{c}.29 \\
2.61 \\
8.97\end{array}$ & $\begin{array}{l}.81 \\
.54 \\
.27 \\
.29\end{array}$ & $\begin{array}{r}4.35 \\
.27 \\
1.36\end{array}$ & $\begin{array}{r}2.70 \\
.81 \\
.54\end{array}$ & $\begin{array}{l}3.76 \\
2.25 \\
\end{array}$ & $\begin{array}{r}29.97 \\
1.08 \\
15.08 \\
.87 \\
3.53\end{array}$ & 3.76 & $\begin{array}{r}3.78 \\
1.62 \\
.54 \\
10.15\end{array}$ & $\begin{array}{l}.58 \\
.29\end{array}$ & 43.24 & 2.44 & $\begin{array}{r}371 \\
348 \\
12 \\
11 \\
344 \\
327 \\
1 \\
16 \\
367 \\
331 \\
8 \\
28 \\
266 \\
215 \\
8 \\
43\end{array}$ \\
\hline
\end{tabular}


Table VI. gives the percentile frequencies of the associative aids distributed with respect to the three classes named above and for each series used in the experiment. Some of the outstanding features in this table are: (I) Nearly all of the associative aids are connected with both the stimulus and the response, i. $\varepsilon$., with both words of a pair.

(2) The category of 'order and position' has the highest frequencies. (3) The second highest frequencies are in the associations of predication and of patterns for English pairs, and in the associations of rhythm for German-English vocabularies and for nonsense syllables pairs. (4) If we except the associations of contiguity, we can say that associative aids connected with words of the mother tongue cluster about some likeness in meaning while those that are connected with some foreign language cluster about some likeness in sensory quality. (5) With respect to associations of order and position we can say that these are less frequent with familiar material than with strange material.

If from these facts we attempt to infer the influence of the quality of an association upon its function, it seems that logical associations reduce the rate of learning much more than sensory ones, and are therefore much more important for this function. The evidence for this statement is proposition No. 3 above and the fact that the one L.T. of the first day for the familiar pairs is $6.29^{\prime \prime}$ and for the strange pairs it is $14.69^{\prime \prime}$. We have seen that associative aids of all kinds are favorable to learning. We now see that the degree of their favorableness varies with their quality, the logical being much more favorable than the sensory.

A word of explanation should be added for the high frequencies for the associations of order and position. The series were learned always in the same order from day to day, and this condition no doubt accounts for their high frequencies.

The next question concerns the relation of associative aids to other associative and reproductive tendencies. By the latter I mean those that interfere with the learning process and cause a wrong response. Since associative aids are also 
a source of error, it is possible to determine the frequency of error due to this source as compared with that due to other sources, and therefore the comparative value of these associative tendencies for learning and retention. In analyzing these errors, I have followed the same general plan as for the associative aids, but had to make some omissions and additions of the categories. I omitted the response immediately connected with stimulus only and with response only and have added 'mediate with stimulus,' 'mediate with response,' and 'perseveration.' The mediate associations were frequent enough to demand this, and since they were rather unusual, I shall reproduce some specimens:

Mediate through stimulus by similarity in sound or sight of

Mediate through response by similarity in sound or sight of

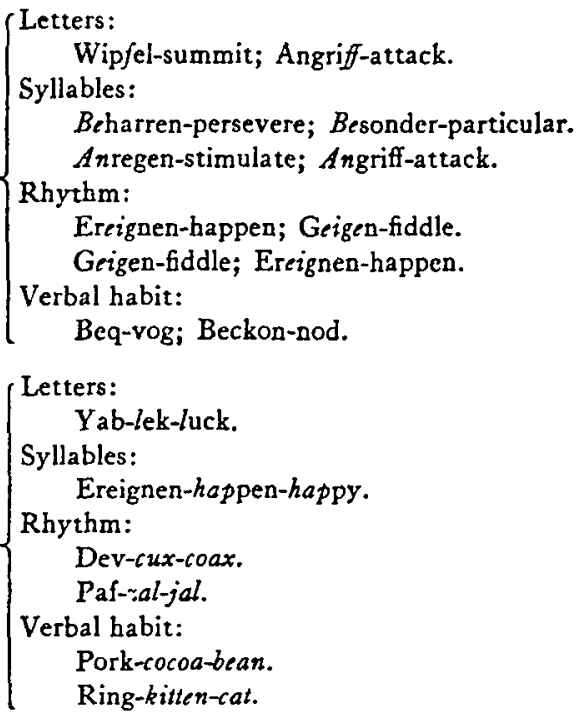

In the above examples, the last word is the response given and the first word is the stimulus. The elements in the stimulus or other word printed in italics are the factors which in the judgment of the experimenter might have led to the response named. For example, Ereignen was often responded to by fiddle, probably because the sound of eig occurs both in Ereignen and Geigen. There is no proof that ereignen suggested geigen, and that geigen then suggested fiddle. It is more probable that both happen and fiddle during the 
early stages of learning were associated with the sound of eig, and sometimes it suggested happen and sometimes fiddle. But this type of association I have called mediate because a certain stimulus suggested a second response whose stimulus had something in common with the first stimulus.

Besides mediate associations, I have added perseveration as a category for the distribution of error because many of the responses could not be explained otherwise. The criteria of perseveration were: (I) repetition of a response on the same day after it had been given at its correct place, (2) repetition of a response stimulus after stimulus because the subject could apparently think of no other and knew that it belonged somewhere in the series, (3) when a response was given to a stimulus with which it had no discoverable associative connection.

The criteria of associations of order and position should also be stated at this point. When two or more responses were given in the correct order but out of position, or when a word or syllable was named one position in advance of its proper place, the errors were classified as due to associations of order and position.

Table VII

\begin{tabular}{|c|c|c|c|c|c|c|c|c|c|c|c|c|c|c|c|c|c|c|c|}
\hline & \multicolumn{17}{|c|}{ Per Cent. of Wrong Responses Due to Association } & \multirow{5}{*}{ 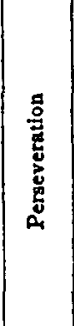 } & \multirow{5}{*}{ 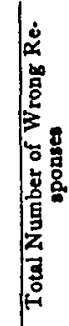 } \\
\hline & \multicolumn{9}{|c|}{ Immediate with Stimulus and Response by } & \multirow{3}{*}{\multicolumn{4}{|c|}{$\begin{array}{l}\text { Mediate with Stimu- } \\
\text { lus by Similanty in } \\
\text { Sound or Sight }\end{array}$}} & \multirow{3}{*}{\multicolumn{4}{|c|}{$\begin{array}{l}\text { Mediate with } \\
\text { Response by Simiglar- } \\
\text { tty in Sound or Sight }\end{array}$}} & & \\
\hline & \multirow{3}{*}{ 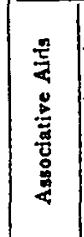 } & \multicolumn{7}{|c|}{ Stmilanty to } & \multirow{3}{*}{ 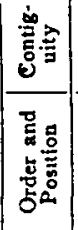 } & & & & & & & & & & \\
\hline & & \multicolumn{3}{|c|}{ Sound or Sight } & \multicolumn{4}{|c|}{ Meanung } & & & & & & & & & & & \\
\hline & & 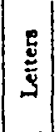 & 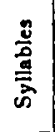 & 参 & 焉 & 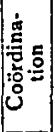 & 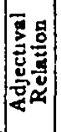 & 总 & & $\underset{\mathbf{g}}{\underline{z}}$ & 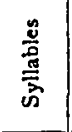 & 量 & 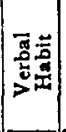 & בัٌ & $\begin{array}{l}\frac{g}{0} \\
\frac{0}{5} \\
\frac{\pi}{2}\end{array}$ & 兽 & 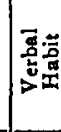 & & \\
\hline $\begin{array}{l}\text { S.B..... } \\
\text { R.C..... } \\
\text { W.S.... } \\
\text { W.P... }\end{array}$ & $\begin{array}{r}14.90 \\
5.55 \\
3.19 \\
3.38 \\
\end{array}$ & .32 & 1.66 & $\begin{array}{r}0.97 \\
.46 \\
.49 \\
7.72 \\
\end{array}$ & $\begin{array}{l}1.62 \\
4.16 \\
1.82 \\
\end{array}$ & & & $\begin{array}{l}0.32 \\
1.39 \\
\end{array}$ & $\begin{array}{l}35.96 \\
42.59 \\
28.05 \\
26.56\end{array}$ & 1.99 & 11.28 & $\begin{array}{r}2.49 \\
1.12 \\
\end{array}$ & $\begin{array}{c}.97 \\
0.16 \\
1.28 \\
\end{array}$ & \begin{tabular}{|}
.97 \\
2.15 \\
4.83 \\
\end{tabular} & $\begin{array}{l}.32 \\
.66\end{array}$ & $\mid \begin{array}{r}5.83 \\
2.77 \\
2.32 \\
30.59 \\
\end{array}$ & $\begin{array}{l}3.24 \\
7.40 \\
.16 \\
.80\end{array}$ & $\begin{array}{l}34.09 \\
35.18 \\
43.49 \\
29.78\end{array}$ & $\begin{array}{l}305 \\
216 \\
602 \\
621\end{array}$ \\
\hline
\end{tabular}

Table VII. gives the results of the distribution of the errors according to their type of association. The noteworthy features of this table are that an average of 35.29 per cent., or little over one third of the errors are due to perseveration. An average of 33.29 per cent. or one third 
are due to associations of order and position. The other third of the errors are distributed chiefly among the associative aids and mediate associations. Only 6.78 per cent., or one fifteenth of the errors, are due to associative aids. In all of these cases, the aid was reproduced instead of the associate. There are almost no errors due to logical associations. It therefore appears that the small per cent. of error due to associative aids and the absence of error due to logical associations are negative confirmations of the importance we have attributed to them for learning and retention. While associations of contiguity are important for learning, they produce many errors before becoming fixed. The most important source of error is due to perseveration. That over one third of the errors must be attributed to some such factor as perseveration may be taken as strong proof for its existence and as a confirmation of the evidence of Müller and Pilzeker who named it. Interference from perseveration occurs chiefly during the early stages of learning while the various associations are in process of formation. After associations are once formed and the series learned, their chances of interference with second series are greatly reduced not only because of their fixed character but also because the learning of the second series is directed by a new and different adjustment or Aufgabe. The present experiment also shows evidence of this, for the four series of associates were learned in immediate succession but I can find no errors or responses that were carried over from one series to the next, and on this basis there is no evidence of perseveration. This, however, does not contradict the role which it plays within the series, and I cannot, therefore, accept De Camp's ${ }^{1}$ evidence as proof. It should be emphasized that perseveration according to the evidence of this experiment is an inhibitive and disintegrating factor in learning. It produces interference and error and allows their ideas to flow away from their anchors. It is so far uneconomical and destroys the adaptability of the mind while the latter is attempting to do its proper work. It, therefore, appears as a symptom of weakness and inefficiency.

1 Psychol. Monoc., 1915, No. 84. 
But it must be remembered that our experiment furnished no measure of whatever positive benefits it might have.

If we examine the facts of Tables V. and VI. with respect to the frequency of the various types as compared with those for free association, we notice many differences. For example, in Table V. there are no categories for superordination, subordination, cause-effect, verbs, participles, verb-object, word-compounding, etc., such as those used by Woodrow and Lowell. All of these excepting verbs, participles, and wordcompounding were in my original table, but none of these types occurred. Those that did occur are distributed very much differently from those in free association, the striking differences being the high frequencies for order and position, patterns, predication, and rhythm. In Table VI. the distribution is still more concentrated, there being only three general types, perseveration, contiguity, and similarity in sensory quality. This is probably due to the fact that associative aids were spontaneous but the responses for the facts of Table VI., excepting the errors due to associative aids, were controlled, i. e., they were selected from the material given and were only misplaced. In a measure, the associative aids were also controlled. They were directed by the Aufgabe to learn the pairs given and had to be adapted to these materials. The Aufgabe and the nature of the materials thus require no correspondence of frequency in types with those of free association.

\section{SumMary II.}

An attempt to classify associative aids under the usual categories for free association shows a much more concentrated distribution with respect to the number of classes, the principal classes being order and position, patterns, predication, and rhythm.

Their relation to other associations as indicated by an analysis of errors shows that only about $7 \%$ of the errors in learning are due to them, leaving $93 \%$ due to other reproductive tendencies the most of which may be classified under perseveration, contiguity and sensory similarity. 
The distribution of the types of associative aids and of the errors in learning has little agreement with that for free association because the former are a form of controlled association.

So far as the function of associative aids is correlated with their type, it appears that those based on meaning are much more effective in learning and retention than those based on sensory quality, but all types have a favorable influence on mental economy. As such they are distinguished from perseveration, which is a disintegrating factor in the work of the mind. 